\title{
Effects of Occupation-Based Intervention for Older People with Mild Dementia in the Institution
}

\section{Syamsul Anwar Sultan Ibrahim, Akehsan Dahlan, Ahmad Zamir Che Daud}

\author{
Faculty of Health Sciences, \\ Universiti Teknologi MARA, Selangor Campus, 42300 Bandar Puncak Alam, Selangor, Malaysia
}

syamsul2893@uitm.edu.my, akehsan@uitm.edu.my, zamir5853@uitm.edu.my

Tel: $+6019-5661965$

\begin{abstract}
Older people with dementia always experience the cognitive difficulties that are believed to impact their daily life significantly. However, information regarding occupation-based intervention toward older people with mild dementia in the institution is inconclusive. The results of this randomized controlled trial indicate a significant difference in cognitive functions, social relationship, and the quality of life. Participants in the experimental group improved significantly compared to the participants in the control group. Engagement in occupational activities should be encouraged to older people with mild dementia in institution to facilitate the cognitive functions, social relationship, and quality of life.
\end{abstract}

Keywords: older people; mild dementia; occupation-based; quality of life

eISSN: 2398-4287@ 2021. The Authors. Published for AMER ABRA cE-Bs by e-International Publishing House, Ltd., UK. This is an open access article under the CC BYNC-ND license (http://creativecommons.org/licenses/by-nc-nd/4.0/). Peer-review under responsibility of AMER (Association of Malaysian Environment-Behaviour Researchers), ABRA (Association of Behavioural Researchers on Asians/Africans/Arabians) and cE-Bs (Centre for Environment-Behaviour Studies), Faculty of Architecture, Planning \& Surveying, Universiti Teknologi MARA, Malaysia.

DOI: https://doi.org/10.21834/ebpj.v6i16.2727

\subsection{Introduction}

It is anticipated that Malaysia will become an ageing country by the year 2030 , in which $16 \%$ of the total population consist of older people and will rise to $22 \%$ by the year 2050 (United Nations, 2013). The changes in society's characteristics lead to the urbanization, thus neglecting the roles toward older parents. Many ageing parents discover themselves being on their own, with a lack of social and financial support and deteriorating health conditions. These will result in many ageing parents been relocated to public or private older people institutions. Increasing numbers of older people produce some consequences in healthcare facilities as older people in Malaysia live longer. More health care services will be required, increasing government expenditure on health-related benefits. One of the conditions that are related to older people is dementia. Dementia is a broad term for diseases that cause a decline in a person's cognitive and memory aspects. It affects individuals' lives ranging from relationships, mood, quality of life and activities of daily functioning (Alzheimer's Associations, 2015). In addition, dementia also interferes with social or occupational functioning (Chertkow et al., 2013). According to the Alzheimer Disease International (2014) report, the prevalence of dementia in Malaysia in 2015 was 123,000, and the number will increase to 261,000 and 590,000 in 2030 and 2050, respectively. These statistics show that promoting healthy cognition has become the priority and needs to minimize and prevent burdens for individual and societal associated with dementia in the older population.

Various programs could be conducted to prevent deterioration, maintain or enhance the domains in life as above, for example, cognitive stimulation, specific cognitive training, and cognitive rehabilitation program. However, such a program is conducted in

eISSN: 2398-42870 2021. The Authors. Published for AMER ABRA cE-Bs by e-International Publishing House, Ltd., UK. This is an open access article under the CC BYNC-ND license (http://creativecommons.org/licenses/by-nc-nd/4.0/). Peer-review under responsibility of AMER (Association of Malaysian Environment-Behaviour Researchers), ABRA (Association of Behavioural Researchers on Asians/Africans/Arabians) and CE-Bs (Centre for Environment-Behaviour Studies), Faculty of Architecture, Planning \& Surveying, Universiti Teknologi MARA, Malaysia.

DOI: https://doi.org/10.21834/ebpj.v6i16.2727 
developed countries and designed for older people living in the community. Most of the program is often conducted as a 'stand-alone' program and seldom involve engagement in meaningful and valued occupations or activities which are not aligned and congruent with the fundamentals and values in Occupational Therapy (OT) practices. Hence, this study aims to identify the effects of an occupationbased intervention on cognitive functions, social relationship, and quality of life for older people with mild dementia in the institution.

\subsection{Literature Review}

Occupational therapy intervention always integrates occupation-based activity in enabling an individual to regain, retain, and promote functional ability after experiencing injury or illness. The basis of the occupational therapy's philosophy came from recognizing the importance of meaningful activity for an individual concerning support of their functional ability, quality of life, and the devastating effect of inactivity. Occupational Therapy will increase or enhance the skills of an individual in the following categories of occupations as detailed out in Occupational Therapy Practice Framework (3rd Ed.) (American Occupational Therapy Association - AOTA, 2014) such as basic activities of daily living (BADL), instrumental activities of daily living (IADL), preparation and participation in rest and sleep, educational activities, work-related activities, play activities, leisure activities, and social participation.

In relation to identify the impairments or dysfunctions in the performance, occupational therapists need to evaluate specific components such as motor areas, cognitive domains, psychological, and psychosocial to become the basis in tailoring the intervention according to the needs and interest of the person. Furthermore, occupational therapists play a significant role in understanding the effects of the disease toward older people with mild dementia. It is important to develop and modify the intervention according to the severity of the impairment (Yuill \& Hollis, 2011).

Engagement in occupational activities has been found to have the positive impact on improving cognitive functions among older people in institutions (Peralta et al., 2017) and provide a significant change in physical, psychological and social domains of quality of life (Dahlan \& Sultan Ibrahim, 2015). Besides, older people with dementia also benefited from the engagement in occupational activities such as improved significantly in recognition test and word-list recall (Kim et al., 2016), influence on better cognitive and physical functions (Min et al., 2015), significant improvements in daily living activities, cognition, and reduce depression (Cho et al., 2015), and reducing the behavioural and psychological symptoms of dementia as well as maintaining the executive function (Murai \& Yamaguchi, 2017). In addition, a recent study related to occupational activities also has positive outcomes in improving cognitive functions, reducing depression as well as improving the quality of life for older people with mild dementia (Kim, 2020).

\subsection{Methodology}

\subsection{Study Design}

Pre-Test-Post-Test parallel groups Randomized Controlled Trial (RCT) design used to determine the effect of the occupation-based intervention compared to the control group.

\subsection{Study Setting and Participants}

The study has been conducted at governmental-funded older people institution managed and financed by the Department of Social Welfare, Malaysia. It is well established and one of the largest public-funded institutions for older people. All of the residents were screened, and thirty-two participants were recruited into this study according to the following inclusion criteria (i) older people age 60 and above; (ii) lived in the institution for at least six months; (iii) Minimal dependence to Independent in the activity of daily living (scores 91 - 100 in Barthel Index); (iv) Mild dementia (Scores 1 for mild dementia in Clinical Dementia Rating Scale); and (v) No depression (scores less than 5 in Geriatric Depression Scale - short form).

\subsection{Sampling and Randomization}

Random sampling strategy has been used in this study to randomize the participants into two groups, i.e. experimental group or control group. Both researcher and the participants will not receive information regarding which group (either control or experimental group) they will belong to. Participants who meet the inclusion criteria and willing to participate in the program will be listed in an original list. Each participant will be given a random numerical identification or unique identifier by an independent assistant from number 00 . Subsequently, their names will be erased from the original list. The participants have been assigned into two groups (control or experimental group) through randomization using Random Allocation Software (Saghaei, 2004). To ensure the study's blinding, the following strategies have been used (i) not allowing participants in the control group to participate in the occupational activities. This will assist in blinding and preventing the contamination for the participants in the control group; (ii) the participants in the experimental group cannot discuss activities carried out during the program. This will also help in preventing from contamination for the participants in the control group; (iii) the study measures were conducted by two independent occupational therapists. Therefore, the study will be protected from the interpretation bias. The final allocation for this study is 16 participants for each group.

\subsection{Intervention Protocol}

Both intervention and control groups received seven weeks of intervention throughout the study. The intervention group will receive a program called an occupation-based intervention and usual occupational therapy intervention. The occupation-based intervention has been designed to be conducted in 2 sessions (Session 1 and Session 2) per week for seven weeks, as shown in Table 1 . There is a 
link between session one and session 2. Session 1 mainly acts as preparatory for Session 2. Activities in Session 1 often related to essential components of cognition, such as orientations, recognitions, awareness, perceptions and memory. In session 2, the activities are related to session one and related to occupational activities such as cooking, shopping, personal hygiene, and leisure and recreational activities. Session 2 often combining the ability gained or stimulated in session 1 . The intervention has been designed in group sessions. Each session consisted of 5-6 numbers of participants. The trained occupational therapist facilitated the sessions. Session 1 (activity 1 and 2) will be conducted for about $45-60$ minutes. Session 2 (Activity 1 and 2) will be conducted for about $60-$ 120 minutes. Hence, each participant in the experimental group will receive between $315-420$ minutes for Session 1 and will be received between 420 - 840 minutes for Session 2. Therefore, each participant in the experimental group will receive between $735-$ 1260 minutes of intervention. Participants in the control group only received the usual intervention by an occupational therapist who works in the institutions for seven weeks.

Table 1. Occupation-Based Intervention for Experimental Group

\begin{tabular}{lll}
\hline Weekly Activity & Session One & Session Two \\
\hline Week 1 & Activity 1 & Activity 1 \\
& Introductory Session & Introductory Session \\
& Activity 2 & Activity 2 \\
Week 2 & You \& Your Occupations & Group Project \\
& Activity 1 & Activity 1 \\
& Introductory Session & Introductory Session \\
Week 3 & Activity 2 & Activity 2 \\
& Sensory Recognition Activity & Cooking \\
& Activity 1 & Activity 1 \\
& Introductory Session & Introductory Session \\
Week 4 & Activity 2 & Activity 2 \\
& Naming the Voice \& Sound & Movies \\
& Activity 1 & Activity 1 \\
& Introductory Session & Introductory Session \\
Week 5 & Activity 2 & Activity 2 \\
& Picture Recognition Activity & Mini Zoo \\
& Activity 1 & Activity 1 \\
& Introductory Session & Introductory Session \\
Week 6 & Activity 2 & Activity 2 \\
& Picture Categorization Activity & Personal Hygiene \\
& Activity 1 & Activity 1 \\
& Introductory Session & Introductory Session \\
Week 7 & Activity 2 & Activity 2 \\
& Money Management Activity & Shopping \\
& Activity 1 & Activity 1 \\
& Introductory Session & Introductory Session \\
& Activity 2 & Activity 2 \\
& Creative Activity & Group Celebration \\
\hline
\end{tabular}

\subsection{Research Instruments}

Three research instruments used in this study. (1) Lowenstein Occupational Therapy Cognitive Assessment - Geriatric (LOTCA-G), (2) Friendship scale (FS) and (3) Brief Version of World Health Organisation - Quality of Life (WHOQOL-Bref). The LOTCA-G is an Occupational Therapy assessment that consists of 23 subtests in seven cognitive areas (Erez \& Katz, 2004). The LOTCA-G was validated to Bahasa Malaysia in 2015, and the results indicated high convergence validity between the English version and the Malay version of LOTCA-G (Natar, et al., 2015). Friendship Scale (Hawthorne, 2006) was chosen to evaluate the level of social relations amongst older people in the institution. It consists of six short, user-friendly and straightforward questionnaires that can easily be understood by the participants and scores by the researcher and previously used to the older person in Malaysia who live in the nursing homes (Nikmat, Al-Mashoor \& Hashim, 2015). Data regarding the quality of life were gathered using the Malay version of the WHOQOLBref (WHOQOL Group, 1995; Hasanah et al., 2003). This instrument provides the global and specific construct or domain of the quality of life such as the overall quality of life, health status related to the quality of life and quality of life-related to four domains, i.e. physical, psychological, social, and environment.

\subsection{Data Analysis}

Data were analyzed using Statistical Package for the Social Sciences (SPSS) Version 21. The normality test has been conducted on all of the dependent variables (continuous) using the Shapiro-Wilk test for normality and it was found that the data did not fit the standard normal distribution. Therefore, the Mann-Whitney $U$ test was used in accepting or rejecting the null hypothesis. Alpha level of 0.05 was used to determine any significant difference between the pre and post values. Acceptance or rejection of the hypothesis is based on a $95 \%$ confidence interval $(\mathrm{Cl})(\mathrm{p}<0.05)$.

\subsection{Findings}

\subsection{Demographic characteristics}


The socio-demographic characteristics of participants are shown in Table 2. There are two age groups in both experimental and control groups and both groups have equal number of participants $(n=16)$. The participants are predominantly male and Malay race in both experimental and control groups. The length of stay in the institution ranging from 6 months to 96 months. No statistically significant differences were found between experimental group and control group on demographic variables therefore confirming homogeneity.

Table 2. Socio-demographic characteristics of participants

\begin{tabular}{lcc}
\hline Demographics & $\begin{array}{c}\text { Experimental Group } \\
(\mathrm{n} / \%)\end{array}$ & $\begin{array}{c}\text { Control Group } \\
(\mathrm{n} / \%)\end{array}$ \\
\hline Age & & \\
60 to 74 years old & $8(50.00)$ & $9(56.25)$ \\
Above 75 years old & $8(50.00)$ & $7(43.75)$ \\
Total & $16(100)$ & $16(100)$ \\
& & \\
Gender & $13(81.25)$ & $11(68.75)$ \\
Male & $3(18.75)$ & $5(31.25)$ \\
Female & $16(100)$ & $16(100)$ \\
Total & & \\
& & \\
Race & $10(62.50)$ & $12(75.00)$ \\
Malay & $4(25.00)$ & $1(6.25)$ \\
Chinese & $2(12.50)$ & $2(12.50)$ \\
Indian & - & $1(6.25)$ \\
Others & $16(100)$ & $16(100)$ \\
Total & & \\
& & - \\
Length of Stay in Institution & $2(12.50)$ & $8(50.00)$ \\
6 to 24 months & $8(50.00)$ & $6(37.50)$ \\
25 to 48 months & $4(25.00)$ & $2(12.50)$ \\
49 to 72 months & $2(12.50)$ & $16(100)$ \\
73 to 96 months & $16(100)$ & \\
Total & & \\
\hline $\mathrm{n}=$ number of participants & &
\end{tabular}

\subsection{Pre and Post Intervention}

Before the intervention, there was no statistically significant differences in cognitive functions, social relationship, and quality of life between the experimental and control groups thus confirming the homogeneity. After seven weeks of intervention, all 32 participants from both groups completed the intervention program. The post-test results indicated that participants in the experimental group improved significantly in six domains in cognitive functions measured by LOTCA-G such as orientation (orientation for time), perception (objects constancy), visuomotor organization (block design, drawing a clock), thinking operations (categorization), memory (everyday objects), and attention and concentration; social relationship as measured by Friendship Scale; and all domains of quality of life measured by WHOQoL-Bref (physical, psychological, social, and environment) compared to the control group with effect sizes ranging from medium to large as shown in Table 3.

Table 3. Differences of the score for LOTCA-G, Friendship Scale, and WHOQOL-Bref.

\begin{tabular}{|c|c|c|c|c|c|c|c|c|}
\hline LOTCA-G & Groups & $\begin{array}{l}\text { Pre } \\
\text { Median (IQR) }\end{array}$ & $\begin{array}{l}\text { Post } \\
\text { Median (IQR) }\end{array}$ & $n$ & $\mathrm{u}$ & $z$ & $p$ & $r$ \\
\hline \multicolumn{9}{|l|}{ Orientation } \\
\hline \multirow[t]{2}{*}{ Orientation for Place } & $E$ & $6.00(5.25-6.75)$ & $6.00(6.00-7.00)$ & 16 & 116.000 & -0.493 & 0.62 & \\
\hline & C & $6.00(5.25-6.75)$ & $6.00(5.25-6.75)$ & 16 & & & & \\
\hline \multirow[t]{2}{*}{ Orientation for Time } & $E$ & $4.00(3.00-4.00)$ & $4.00(4.00-5.00)$ & 16 & 65.500 & -2.620 & $0.02^{*}$ & 0.46 \\
\hline & C & $4.00(3.00-4.00)$ & $4.00(3.00-4.00)$ & 16 & & & & \\
\hline \multicolumn{9}{|l|}{ Perception } \\
\hline \multirow[t]{2}{*}{ Visual Identification of Objects } & $E$ & $4.00(4.00-4.00)$ & $4.00(4.00-4.00)$ & 16 & 128.000 & 0.000 & 1.00 & \\
\hline & C & $4.00(4.00-4.00)$ & $4.00(4.00-4.00)$ & 16 & & & & \\
\hline \multirow[t]{2}{*}{ Visual Identification of Shapes } & $E$ & $4.00(4.00-4.00)$ & $4.00(4.00-4.00)$ & 16 & 120.000 & -0.597 & 0.55 & \\
\hline & C & $4.00(4.00-4.00)$ & $4.00(4.00-4.00)$ & 16 & & & & \\
\hline \multirow[t]{2}{*}{ Overlapping Figures } & $E$ & $3.00(3.00-4.00)$ & $3.50(3.00-4.00)$ & 16 & 105.500 & -0.958 & 0.34 & \\
\hline & C & $3.00(3.00-4.00)$ & $3.00(3.00-4.00)$ & 16 & & & & \\
\hline \multirow[t]{2}{*}{ Object Constancy } & $E$ & $4.00(4.00-4.00)$ & $4.00(4.00-4.00)$ & 16 & 79.500 & -2.425 & $0.02^{*}$ & 0.43 \\
\hline & C & $4.00(3.00-4.00)$ & $4.00(3.00-4.00)$ & 16 & & & & \\
\hline \multicolumn{9}{|l|}{ Spatial Perception } \\
\hline \multirow[t]{2}{*}{ a. Directions on Body } & $E$ & $4.00(4.00-4.00)$ & $4.00(4.00-4.00)$ & 16 & 128.000 & 0.000 & 1.00 & \\
\hline & C & $4.00(4.00-4.00)$ & $4.00(4.00-4.00)$ & 16 & & & & \\
\hline \multirow[t]{2}{*}{ b. Direction in Front } & $E$ & $4.00(3.00-4.00)$ & $4.00(3.00-4.00)$ & 16 & 105.500 & -0.979 & 0.33 & \\
\hline & C & $3.50(3.00-4.00)$ & $3.50(3.00-4.00)$ & 16 & & & & \\
\hline \multirow[t]{2}{*}{ c. Spatial Relations } & $E$ & $3.00(2.00-4.00)$ & $3.00(2.00-4.00)$ & 16 & 113.000 & -0.607 & 0.55 & \\
\hline & C & $4.00(2.25-4.00)$ & $3.50(2.00-4.00)$ & 16 & & & & \\
\hline \multicolumn{9}{|l|}{ Praxis } \\
\hline \multirow[t]{2}{*}{ Motor Imitation } & $E$ & $3.00(2.00-3.00)$ & $3.00(2.00-3.00)$ & 16 & 121.500 & -0.269 & 0.79 & \\
\hline & C & $3.00(2.25-3.00)$ & $3.00(2.00-3.00)$ & 16 & & & & \\
\hline
\end{tabular}




\begin{tabular}{|c|c|c|c|c|c|c|c|c|}
\hline \multirow[t]{2}{*}{ Utilization of Objects } & $E$ & $4.00(3.00-4.00)$ & $4.00(3.25-4.00)$ & 16 & 116.000 & -0.575 & 0.57 & \\
\hline & C & $4.00(4.00-4.00)$ & $4.00(3.00-4.00)$ & 16 & & & & \\
\hline \multirow[t]{2}{*}{ Symbolic Actions } & $E$ & $4.00(4.00-4.00)$ & $4.00(3.00-4.00)$ & 16 & 125.000 & -0.139 & 0.90 & \\
\hline & C & $4.00(3.25-4.00)$ & $4.00(3.00-4.00)$ & 16 & & & & \\
\hline \multicolumn{9}{|l|}{ Visuomotor Organization } \\
\hline \multirow[t]{2}{*}{ Copy Geometric Forms } & E & $3.00(3.00-4.00)$ & $3.50(3.00-4.00)$ & 16 & 120.000 & -0.349 & 0.73 & \\
\hline & C & $3.00(3.00-4.00)$ & $4.00(3.00-4.00)$ & 16 & & & & \\
\hline \multirow[t]{2}{*}{ Two Dimensional Model } & $E$ & $3.00(2.00-4.00)$ & $3.00(2.00-4.00)$ & 16 & 127.000 & -0.040 & 0.97 & \\
\hline & C & $3.00(2.25-4.00)$ & $3.00(2.25-4.00)$ & 16 & & & & \\
\hline \multirow[t]{2}{*}{ Pegboard Construction } & $E$ & $4.00(3.00-4.00)$ & $4.00(3.00-4.00)$ & 16 & 112.000 & -0.751 & 0.45 & \\
\hline & C & $4.00(3.00-4.00)$ & $4.00(3.25-4.00)$ & 16 & & & & \\
\hline \multirow[t]{2}{*}{ Block Design } & $E$ & $3.00(3.00-4.00)$ & $3.50(3.00-4.00)$ & 16 & 83.000 & -1.991 & $0.05^{*}$ & 0.35 \\
\hline & C & $3.00(3.00-3.00)$ & $3.00(3.00-3.00)$ & 16 & & & & \\
\hline \multirow[t]{2}{*}{ Reproduction of a Puzzle } & $E$ & $3.00(2.25-4.00)$ & $3.00(2.25-3.75)$ & 16 & 122.000 & -0.249 & 0.80 & \\
\hline & C & $3.00(3.00-4.00)$ & $3.00(2.25-3.00)$ & 16 & & & & \\
\hline \multirow[t]{2}{*}{ Drawing a Clock } & $E$ & $3.00(2.00-3.75)$ & $3.00(3.00-4.00)$ & 16 & 77.000 & -2.048 & $0.04^{*}$ & 0.36 \\
\hline & C & $3.00(2.00-3.75)$ & $2.50(2.00-3.00)$ & 16 & & & & \\
\hline \multicolumn{9}{|l|}{ Thinking Operations } \\
\hline \multirow[t]{2}{*}{ Categorization } & $E$ & $2.00(2.00-3.00)$ & $3.00(2.00-3.00)$ & 16 & 72.500 & -2.388 & $0.02^{*}$ & 0.42 \\
\hline & C & $2.00(2.00-3.00)$ & $2.00(2.00-2.00)$ & 16 & & & & \\
\hline \multirow[t]{2}{*}{ Pictorial Sequence } & $E$ & $3.00(3.00-3.00)$ & $3.00(3.00-3.75)$ & 16 & 104.000 & -1.438 & 0.15 & \\
\hline & C & $3.00(3.00-3.00)$ & $3.00(3.00-3.00)$ & 16 & & & & \\
\hline \multicolumn{9}{|l|}{ Memory } \\
\hline \multirow[t]{2}{*}{ A Famous Personality } & $E$ & $3.00(2.25-3.00)$ & $3.00(3.00-3.00)$ & 16 & 105.500 & -1.078 & 0.28 & \\
\hline & C & $3.00(2.00-3.00)$ & $3.00(2.00-3.00)$ & 16 & & & & \\
\hline \multirow[t]{2}{*}{ A Personal Possession } & $E$ & $3.00(2.00-3.75)$ & $3.00(3.00-4.00)$ & 16 & 94.000 & -1.349 & 0.18 & \\
\hline & C & $3.00(2.00-3.75)$ & $2.50(2.00-3.00)$ & 16 & & & & \\
\hline \multirow[t]{2}{*}{ Everyday Objects } & $E$ & $3.00(3.00-3.00)$ & $3.00(3.00-4.00)$ & 16 & 76.500 & -2.253 & $0.02^{*}$ & 0.40 \\
\hline & C & $3.00(3.00-3.00)$ & $3.00(2.00-3.00)$ & 16 & & & & \\
\hline \multirow[t]{2}{*}{ Attention and Concentration } & $E$ & $3.50(3.00-4.00)$ & $4.00(4.00-4.00)$ & 16 & 36.500 & - 3.692 & $0.02^{*}$ & 0.65 \\
\hline & C & $3.00(2.00-4.00)$ & $3.00(2.00-3.00)$ & 16 & & & & \\
\hline \multirow[t]{2}{*}{ Friendship Scale (FS) } & $E$ & $6.00(4.00-7.00)$ & $9.50(8.00-11.75)$ & 16 & 48.500 & -3.017 & $0.02^{*}$ & 0.53 \\
\hline & C & $5.00(4.00-7.75)$ & $6.00(4.00-8.00)$ & 16 & & & & \\
\hline \multicolumn{9}{|l|}{ WHOQoL -Bref Domains } \\
\hline \multirow[t]{2}{*}{ Domain 1: Physical Health } & $E$ & $12.00(10.00-14.50)$ & $14.00(13.25-15.00)$ & 16 & 69.000 & -2.252 & $0.03^{*}$ & 0.40 \\
\hline & C & $12.50(11.25-14.00)$ & $12.50(11.25-14.00)$ & 16 & & & & \\
\hline \multirow[t]{2}{*}{ Domain 2: Psychological Health } & $E$ & $13.50(12.00-15.75)$ & $15.00(14.00-16.75)$ & 16 & 65.500 & -2.421 & $0.02^{*}$ & 0.43 \\
\hline & C & $14.00(13.00-16.00)$ & $14.00(13.00-15.00)$ & 16 & & & & \\
\hline \multirow[t]{2}{*}{ Domain 3: Social Relationships } & $E$ & $6.00(5.00-6.75)$ & $7.00(6.00-8.50)$ & 16 & 15.000 & -4.443 & $0.02^{*}$ & 0.79 \\
\hline & C & $5.00(5.00-6.00)$ & $5.00(5.00-6.00)$ & 16 & & & & \\
\hline \multirow[t]{2}{*}{ Domain 4: Environment } & $E$ & $15.00(14.00-16.75)$ & $16.00(16.00-18.00)$ & 16 & 66.000 & -2.410 & $0.02^{*}$ & 0.43 \\
\hline & C & $16.00(15.00-16.00)$ & $15.50(14.25-16.00)$ & 16 & & & & \\
\hline
\end{tabular}

$\mathrm{E}=$ experimental, $\mathrm{C}=$ control, $\mathrm{IQR}=$ interquartile range, $\mathrm{n}=$ number of participants, $\mathrm{r}=$ effect size

\subsection{Discussion}

The present study investigates the effects of an occupation-based intervention on cognitive functions, social relationship, and quality of life for older people with mild dementia living in an institution. Findings from the study suggested that occupation-based intervention was beneficial in improving some components in the domain of cognitive functions, social relationship and quality of life for older people with mild dementia in the institution. Elements in six out of seven domains in cognitive functions were beneficial from this occupationbased intervention. This is aligned with the findings from previous literature regarding the engagement in occupational activities toward improving cognitive functions among older people in institutions (Min et al., 2015; Cho et al., 2015; Kim et al., 2016; Peralta et al., 2017), improving social relations between older people and significantly improved in quality of life (Dahlan \& Sultan lbrahim, 2015). However, some of the components of cognitive functions measured by LOTCA-G were found not being improved in this present study. This is probably because the participants in this study are all categorized in the early stage of dementia. The deterioration of the disease affects each individual in a different way (WHO, 2017).

In the aspect of social relationship, this occupation-based intervention positively affects the social relationship among older people with mild dementia in the institution. This is because the activities in the program were carried out in a group session where older people will have the opportunity to know each other and complete every session of the program. Other variables include the nature of the activity where they need to work in pair, working in a group, sharing, and exchanging their ideas together. This will help break the barriers between them before enrollment in the intervention program, providing self-efficacy and confidence and eventually facilitating success during engagement in activity (Shin et al., 2009).

The occupation-based intervention program's characteristics could mediate the significant changes in the quality of life. This program provides meaningful and person-centred occupational activities for the participants. The selection of a meaningful occupation involves values, benefits, motivation and readiness to engage. It could be past activities, activities related to previous life roles, or a new activity that they want to engage with where it was found to facilitate wellbeing (Harmer \& Orrell, 2008). Person-centred activity in this 
intervention context focuses on the participants' strength (rather than focusing on dementia and its associate impairments), by reflecting lifetime experience, a skill gained, interest, preference and abilities through-out lifetime. These are aligned with the fundamental principles of successful Cognitive Stimulation Therapy (Spector et al., 2005). This intervention also has been designed to be delivered in a delightful way in which will fulfil the objectives including simple, fun, and enjoyable delivery; active involvement and inclusion from all participants in the group, multi-choice of activities, and always providing prompt, guide and encouragement toward throughout the session.

Limitation of this study is the limited sample size, gender of the participants and the institution involved. This study also limited to older people with mild dementia while those with moderate and severe dementia were excluded. Further studies should enroll a more significant number of samples comprising a balance number in the gender, stages of dementia and also should be conducted in the multicenter to provide more substantial and conclusive evidence regarding the effects of the occupation-based intervention.

\subsection{Conclusion and Recommendations}

Results indicate that occupation-based intervention program facilitates improvement in cognitive functions, social relationships, and quality of life for older people with mild dementia. Findings from this study suggest that engagement in occupational activities is essential in the milder stages of dementia, potentially minimizing the risk of functional deterioration and improving the quality of life. This research is confined to mild dementia at an elderly institution, so a wide scale of randomized testing might be necessary for further clarification.

\section{Acknowledgement}

We would like to thank the Faculty of Health Sciences, Universiti Teknologi MARA and the Department of Social Welfare for their permission to conduct this study and all participants who provide the information needed.

\section{References}

Alzheimer Disease International. (2014). Dementia in the Asia Pacific Region. London: Alzheimer's Disease International.

Alzheimer's, A. (2015). 2015 Alzheimer's disease facts and figures. Alzheimer's \& dementia: The Journal of the Alzheimer's Association, 11(3), $332-384$.

American Occupational Therapy Association - AOTA (2014). Occupational Therapy Practice Framework : Domain \& Process (3rd ed). AOTA : American Occupational Therapy Association.

Chertkow, H., Feldman, H. H., Jacova, C., \& Massoud, F. (2013). Definitions of dementia and predementia states in Alzheimer's disease and vascular cognitive impairment: consensus from the Canadian conference on diagnosis of dementia. Alzheimer's research \& therapy, 5(1), 1-8.

Cho, M., Kim, D., Chung, J., Park, J., You, H., \& Yang, Y. (2015). Effects of a cognitive-enhancement group training program on daily living activities, cognition, and depression in the demented elderly. Journal of Physical Therapy Science, 27(3), 681-684.

Dahlan, A., \& Sultan Ibrahim, S. A. (2015). Effect of Lively Later Life Programme (3LP) on quality of life amongst older people in institutions. Procedia-Social and Behavioural Sciences, 202, 252-262.

Erez, A. B. H., \& Katz, N. (2004). Cognitive profiles of individuals with dementia and healthy elderly: The Loewenstein Occupational Therapy Cognitive Assessment (LOTCA-G). Physical \& Occupational Therapy in Geriatrics, 22(2), 29-42.

Hasanah, C. I., Naing, L., \& Rahman, A. R. A. (2003). World Health Organization quality of life assessment: brief version in Bahasa Malaysia. Medical Journal of Malaysia, 58(1), 79-88.

Kim, D. (2020). The Effects of a Recollection-Based Occupational Therapy Program of Alzheimer's Disease: A Randomized Controlled Trial. Occupational Therapy International, 2020.

Kim, H. J., Yang, Y., Oh, J. G., Oh, S., Choi, H., Kim, K. H., \& Kim, S. H. (2016). Effectiveness of a community-based multidomain cognitive intervention program in patients with Alzheimer's disease. Geriatrics \& Gerontology International, 16(2), 191-199.

Min, J. Y., Park, J. B., Lee, K. J., \& Min, K. B. (2015). The impact of occupational experience on cognitive and physical functional status among older adults in a representative sample of Korean subjects. Annals of Occupational and Environmental Medicine, 27(1), 11-20.

Mohd Natar, A. K., Nagappan, R., Ainuddin, H. A., Masuri, G., \& Thanapalan, C. K. K. (2015). Psychometric properties of the malay version of the loewenstein occupational therapy cognitive assessment for geriatrics (M-LOTCA-G) among the malaysian elderly population. Educational Gerontology, 41(1), 27-40.

Hawthorne, G. (2006). Measuring social isolation in older adults: development and initial validation of the friendship scale. Social Indicators Research, 77(3), 521-548.

Murai, T., \& Yamaguchi, H. (2017). Effects of a cooking program based on brain-activating rehabilitation for elderly residents with dementia in a Roken facility: A randomized controlled trial. Progress in Rehabilitation Medicine, 2, 20170004.

Nikmat, A. W., Al-Mashoor, S. H., \& Hashim, N. A. (2015). Quality of life in people with cognitive impairment: nursing homes versus home care. International psychogeriatrics, 27(5), 815-824. 
Peralta, P., Gascón, A., \& Latorre, E. (2017). Occupational Therapy Prevents Cognitive Impairment on Long-Term Care Residents. Physical \& Occupational Therapy in Geriatrics, 35(3-4), 119-131.

Saghaei, M. (2004). Random allocation software for parallel group randomized trials. BMC medical research methodology, 4(1), 1-6.

Shin, K. R., Kang, Y., Park, H. J., \& Heitkemper, M. (2009). Effects of exercise program on physical fitness, depression, and self-efficacy of low-income elderly women in South Korea. Public Health Nursing, 26 (6), 523-531.

Spector, A., Thorgrimsen, L., Woods, B., \& Orrell, M. (2005). Our Time: An Evidence-based Programme to Offer Cognitive Stimulation to People with Dementia. Cedar Falls, IA: Freiberg Press

United Nations. (2013). World Population Prospects. The 2012 Revision, Highlights and Advance Table: Economic \& Social Affairs. New York: United Nations.

World Health Organization. (2017). Global action plan on the public health response to dementia 2017-2025.

WHOQOL Group. The world health organization quality of life assessment position paper from World Health Organization. Soc Sic Med 1995; 41 (10): 1403-1409

Yuill, N., \& Hollis, V. (2011). A systematic review of cognitive stimulation therapy for older adults with mild to moderate dementia: an occupational therapy perspective. Occupational therapy international, 18(4), 163-186. 